\title{
Phenology and parasitism rates in introduced populations of Pseudacteon tricuspis, a parasitoid of Solenopsis invicta
}

\author{
Lloyd W. MORRISON ${ }^{1, *}$ and Sanford D. PORTER ${ }^{2}$ \\ ${ }^{1}$ Department of Biology, Southwest Missouri State University, 901 S National Ave., \\ Springfield, MO 65804, USA; ${ }^{2}$ Center for Medical, Agricultural and Veterinary \\ Entomology, USDA-ARS, P.O. Box 14565, Gainesville, FL 32604, USA \\ *Author for correspondence; e-mail:llm868f@smsu.edu
}

Received 1 March 2004; accepted in revised form 7 June 2004

\begin{abstract}
We documented patterns of seasonal abundance and rates of parasitism in introduced populations of Pseudacteon tricuspis Borgmeier, a phorid parasitoid of the red imported fire ant, Solenopsis invicta Buren. Adult P. tricuspis populations were censused at monthly intervals for 1 year at three sites in northern Florida. Censuses were conducted by aspirating phorids attracted to disturbed S. invicta mounds. Pseudacteon tricuspis adults were present in every month at all sites, although abundances varied greatly among sites and over time. The highest densities of flies (up to 453 censused at 10 disturbed $S$. invicta mounds in $30 \mathrm{~min}$ ) were observed in November, and changes in abundance over time were positively correlated among sites. Sex ratios were usually male biased. Parasitism rates were evaluated by collecting workers from field colonies and monitoring them in the laboratory for evidence of parasitism. Parasitism rates were very low - always less than $1 \%$. The average parasitism rate per colony over 16 colonies and 2 years was $0.058 \%$. No pupariation occurred within the first 8 days of collection, suggesting parasitism by $P$. tricuspis induced behavioral changes in parasitized workers that precluded such workers from our collections. If so, true field parasitism rates may be several times higher than measured here, yet still low in an absolute sense. These low parasitism rates can be reconciled with observed adult phorid densities by considering the large number of host ants present at the study sites.
\end{abstract}

Key words: biological control, parasitism, parasitoid, phenology, Pseudacteon tricuspis, Solenopsis invicta

\section{Introduction}

The red imported fire ant, Solenopsis invicta Buren, is one of the most problematic invasive species. Since its introduction into Mobile, Alabama from South America in the 1930s, S. invicta has spread across the southern United States (Callcott and Collins, 1996) and the Caribbean (Davis et al., 2001). This pest has recently turned up in Australia (Nattrass and Vanderwoude, 2001) and New Zealand (Harris, 2001), and could potentially invade many regions around the globe (Morrison et al., 2004). 
Attempts to eradicate this invasive ant from the U.S. using pesticides have failed (Davidson and Stone, 1989; Williams et al., 2001). Quarantine efforts appear to have slowed the expansion of S. invicta (Lockley and Collins, 1990), but it has continued to spread (Callcott and Collins, 1996) and is now established in southern California (Anon., 1999). Recent efforts to control S. invicta have focused on the use of biological agents, including the protozoan pathogens Thelohania solenopsae (Microsporidia: Thelohaniidae) and Vairimorpha invictae (Microsporidia: Burenellidae; Briano et al., 1995; Williams et al., 1999), the fungus Beauveria bassiana (Deuteromycetes; Stimac et al., 1993) and Pseudacteon phorid flies (Diptera: Phoridae; Porter, 1998; Morrison, 2000).

Pseudacteon phorids are solitary parasitoids of Solenopsis fire ants. Adult females inject eggs into live worker ants in rapid aerial attacks. The larva migrates to the head capsule and kills the host prior to pupariation (Porter et al., 1995a). In addition to the direct effect of mortality, the presence of Pseudacteon phorids disrupts the behavior of host Solenopsis workers, resulting in indirect effects on overall colony fitness (Feener and Brown, 1992; Orr et al., 1995, Porter et al., 1995b; Morrison, 1999).

The first successful introduction of Pseudacteon phorids occurred in Gainesville, Florida in 1997, and additional successful introductions have since been made in other regions of Florida and other southeastern states. We recently reported on the establishment and rapid spread of P. tricuspis Borgmeier in northern Florida (Porter et al., 2004). Here we document patterns of abundance and phenology of adult P. tricuspis flies and rates of parasitism of $S$. invicta colonies in the field.

\section{Methods}

\section{Field sites}

This study was conducted at three sites in Alachua County, Florida: Hogtown Creek, Morrill Farm, and Sanders Ranch. The Hogtown Creek site was located on a power line right-of-way near a small stream $\left(29^{\circ} 38^{\prime} \mathrm{N}, 82^{\circ} 23^{\prime} \mathrm{W}\right)$. Morrill Farm and Sanders Ranch sites were located in grazed pastures near ponds $\left(29^{\circ} 49^{\prime} \mathrm{N}, 82^{\circ} 25^{\prime} \mathrm{W}\right.$ and $29^{\circ} 42^{\prime} \mathrm{N}$, $82^{\circ} 28^{\prime} \mathrm{W}$; respectively). Sites were $8-16 \mathrm{~km}$ apart. All three sites had primarily monogyne (i.e., single queen) colonies of red imported fire ants, $S$. invicta, and introduced populations of parasitoid phorid flies, $P$. tricuspis. Introductions of $P$. tricuspis were made at Hogtown Creek 
in September 1997, at Morrill Farm in April 1998, and at Sanders Ranch in November 1999. No other phorids that parasitized S. invicta were present at any of the sites.

\section{Phenology and abundance}

Censuses of adult $P$. tricuspis abundance were conducted at monthly intervals for 1 year, from August 2001 to July 2002. Censuses were always conducted between 11:00 and 16:00 on days when air temperatures ranged between 25 and $34{ }^{\circ} \mathrm{C}$. Flight activity in Pseudacteon is temperature dependent (Morrison et al., 1999a); laboratory experiments have revealed flight activity in $P$. tricuspis is high within this range of air temperatures (SDP, LWM, and J.R. King, unpublished data).

At each site, we disturbed $10 \mathrm{~S}$. invicta colonies by digging into them with a small shovel. Disturbed colonies were $\geq 5 \mathrm{~m}$ apart. Two observers each monitored five disturbed colonies for $P$. tricuspis over a 30-min period, collecting as many flies as possible with an aspirator into clear plastic vials. At times, $P$. tricuspis was too abundant to collect all flies at every mound. In cases where flies were still present at the end of $30 \mathrm{~min}$, we estimated the number of remaining flies.

At the end of the collection period, we temporarily immobilized aspirated flies by introducing carbon dioxide into the collection vials. We used a $10 \times$ hand lens to count and sex all flies. The flies were then exposed to fresh air and, after recovery, released back into the field. The three sites were censused within 2-3 days of each other in every month, with the exception of January 2002 when the sites were censused over a period of 7 days due to intervening cool temperatures.

\section{Parasitism rates}

Rates of parasitism were evaluated at Morrill Farm and Hogtown Creek, the two locations where P. tricuspis has been established the longest. At each site, samples of workers were obtained from: (1) foragers recruiting to baits and (2) the central portion of entire colonies. To obtain foragers, baits ( $\sim 4 \mathrm{~g}$ sections of Oscar Mayer Wieners, pork and turkey) were placed on 5-10 laminated $5 \mathrm{~cm} \times 5 \mathrm{~cm}$ cards spaced around a target mound at $\sim 1 \mathrm{~m}$ distance. Mounds were chosen at random. As foragers recruited to baits, ants on the cards were collected. Collections of foragers were made just after dusk when adult phorids were no longer active. Foragers from four different colonies were sampled in this manner at each site. 
To obtain workers from the central portion of entire colonies, mounds were chosen at random and excavated with a shovel to a depth of $\sim 0.5 \mathrm{~m}$ below the ground surface, at a width of $\sim 0.3 \mathrm{~m}$. Ants and soil were transported to the laboratory, where workers were separated from the soil by drip floatation (Banks et al., 1981). A subsample of several thousand workers was selected randomly from each colony. Four different colonies were sampled in this manner at each site.

Foragers were sampled from different colonies than those excavated, so workers from eight different colonies were sampled at each site in each year. Workers were collected from the same sites by the same methods in November 2000 and again in November 2001. The colonies sampled were chosen at random in each year. It is possible that some colonies were sampled in both years; no attempt was made to avoid or include colonies that may have been previously sampled. Colonies were sampled in November because Pseudacteon phorids are often relatively abundant in the fall (Morrison et al., 1999a; LWM and SDP, personal observations).

Worker ants collected in the field were maintained in vented plastic containers in the laboratory at $\sim 27{ }^{\circ} \mathrm{C}$ with a $12: 12$ light:dark cycle and provided water and sugar water ad libitum. A plaster block saturated regularly with water maintained humidity levels near $100 \%$ in the containers. Ants were examined for evidence of parasitism for 48 days after collection. Dead workers were removed 2 or 3 times a week, and examined 2-3 days after removal for phorid pupae. Pupariation in $P$. tricuspis requires $12-24 \mathrm{~h}$, at which time the worker ant is killed and after which pupae are visible in the detached head capsule (Porter, 1998). Time to pupation was calculated from the collection date to the middle of the interval between each occasion when dead workers were removed. Because dead workers were not removed every day, our estimates of time to pupation may be off by 1-2 days, and should be interpreted as approximate times.

\section{Host ant densities}

To determine whether the low estimates of field parasitism rates could be reconciled with relatively high observed adult phorid abundances, we estimated fire ant densities at the sample sites in October 2001. First, we measured the two-dimensional mound area of all S. invicta colonies within a sample plot. Mounds were generally elliptical in shape, and we calculated mound areas by using the formula for an ellipse $\left(A=\pi^{*}\right.$ a/ $2 * b / 2$, where $a=$ length [long axis] and $b=$ width [short axis]). Plots were established as part of another experiment and, although not of 
equal sizes, were all relatively large and representative of the S. invicta mound density and size distribution in the area.

Next, we estimated the total number of workers associated with each mound using the regression in Macom and Porter (1996), which was determined from monogyne $S$. invicta colonies around Gainesville, FL:

$$
\text { No. of workers }=13.07 \times \text { mound area }\left(\mathrm{cm}^{2}\right)^{1.226}
$$

The estimated total number of workers for each mound was summed over the sample plot, and the cumulative number of workers was divided by the area of the plot (in ha) to obtain an estimate of the total number of $S$. invicta workers per ha.

\section{Results}

Phenology and abundance

Pseudacteon tricuspis adults were present at all sites in every month (Figure 1). Densities varied greatly among sites and over time, ranging from 1 to 453 adult $P$. tricuspis censused per collection. Although much variation existed, some patterns are evident. The abundance of $P$. tricuspis

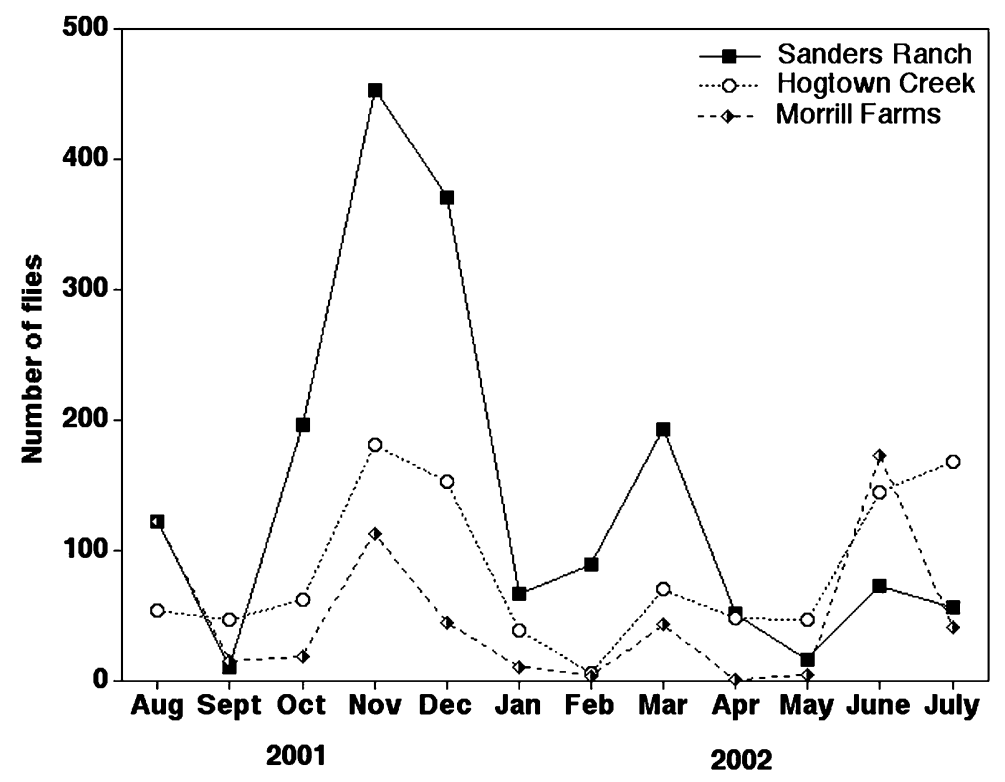

Figure 1. Abundance of Pseudacteon tricuspis phorid flies found at 10 disturbed Solenopsis invicta fire ant mounds in a 30 min collection period at three sites over 12 consecutive months. 
Table 1. Densities of $S$. invicta fire ant workers and average abundances of adult $P$. tricuspis phorids at three sites

\begin{tabular}{lllll}
\hline Site & $\begin{array}{l}\text { Plot area } \\
\left(\mathrm{m}^{2}\right)\end{array}$ & $\begin{array}{l}\text { Mound } \\
\text { area }\left(\mathrm{m}^{2} / \text { ha }\right)\end{array}$ & $\begin{array}{l}\text { Estimated \# of } \\
\text { workers/ha }\end{array}$ & $\begin{array}{l}\text { Average adult } \\
\text { fly abundance }\end{array}$ \\
\hline Sanders Ranch & 873 & 39.8 & $29,432,561$ & 142 \\
Morrill Farms & 788 & 28.2 & $18,469,259$ & 49 \\
Hogtown Creek & 3338 & 20.4 & $14,403,693$ & 85 \\
\hline
\end{tabular}

was consistently highest at Sanders and lowest at Morrill from October 2001 through April 2002. Average fly densities for the 12-month period ranged from 142 at Sanders Ranch to 49 at Morrill Farms (Table 1).

Fly densities tended to increase and decrease in a similar temporal pattern across all sites, with peaks in November, March, and June/July, separated by troughs in September, January/February, and April/May. Changes in fly abundance from month to month were positively correlated between two of the three pairs of sites (Morrill and Hogtown: $r=0.58, p=0.047$; Sanders and Hogtown: $r=0.58, p=0.045$; Morrill and Sanders: $r=0.32, p=0.32$ ). The highest population densities were reached at Sanders and Hogtown in November 2001. Although fly densities were relatively high at Morrill at this time, the highest density at Morrill occurred in June 2002.

We censused a total of 3,311 P. tricuspis phorids across all sites and dates. Of these 3,311, we aspirated and sexed 2,826 (85\%). The remaining $15 \%$ represent flies that were not aspirated due to high abundances (see Methods). Sex ratios were usually male biased, ranging as high as seven males per female in one monthly interval (Figure 2). Females outnumbered males in only four of 30 total collections. Of the collected flies, 2051 flies were male and 775 were female, for an overall 2.65 to 1 maleto-female ratio. Females were easier to aspirate because they usually hovered just above workers they were attempting to parasitize, whereas males often flew erratically over the workers, interacting with other males and attempting to mate with females. Thus our measures of sex ratios may slightly underestimate the actual magnitude of the male bias.

\section{Parasitism rates}

Parasitism rates of workers collected in the field were very low - always less than $1 \%$ (Table 2). About half the samples of S. invicta workers (15 of 32) contained no P. tricuspis pupae at all. Only 31 total pupae were found, although we evaluated $>74,000$ worker ants. The mean parasitism rate per sample of workers, averaged over eight colonies in each 


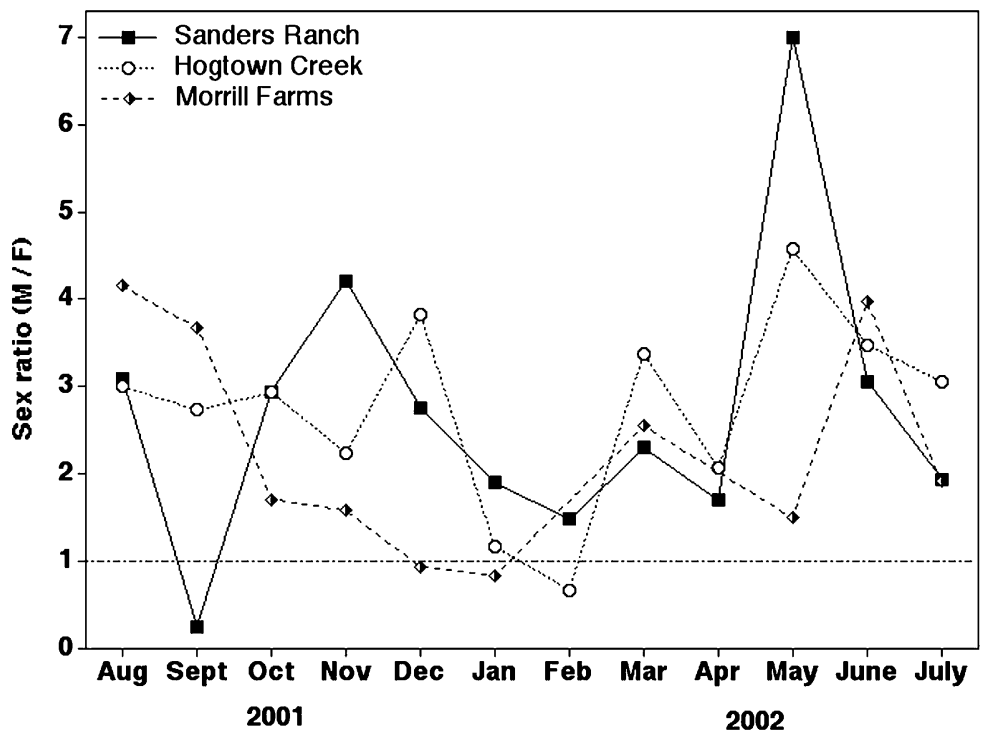

Figure 2. Sex ratios of Pseudacteon tricuspis phorid flies found at 10 disturbed Solenopsis invicta fire ant mounds in a 30 min collection period at three sites over 12 consecutive months. The horizontal dashed line represents a one-to-one ratio. Collections consisting of $<5$ flies are not represented $(n=2)$.

year, was $0.057 \%$ in 2000 and $0.058 \%$ in 2001 . There were no significant differences in percentage parasitism either between sites or between locations of collected workers, in either year (all $p \gg 0.05$; MannWhitney tests).

If parasitism is calculated on the basis of total number of workers evaluated in each year (i.e., pooling all samples together), rates are even lower: $0.039 \%$ in 2000 and $0.043 \%$ in 2001 . These low rates of pupariation are not likely an artifact of our laboratory techniques of maintaining and monitoring field-collected workers, as we often find parasitism rates as high as $20-30 \%$ in worker ants subject to $P$. tricuspis attack in the laboratory (SDP, unpublished data).

Of the 31 pupae, 22 emerged as adults. More males than females emerged (15 compared to 7 , respectively). This was only marginally significant ( $p=0.09$, two-tailed binomial test), although this test lacked power due to the small sample size.

Phorid pupae were found to be present in dead workers from approximately day 9 to day 44 after collection, although $94 \%$ of the pupae were found from approximately day 9 to day 29 (Figure 3). Remarkably, no larvae pupariated within the first 8 days after collection of workers. Even assuming our estimates of time to pupation were 


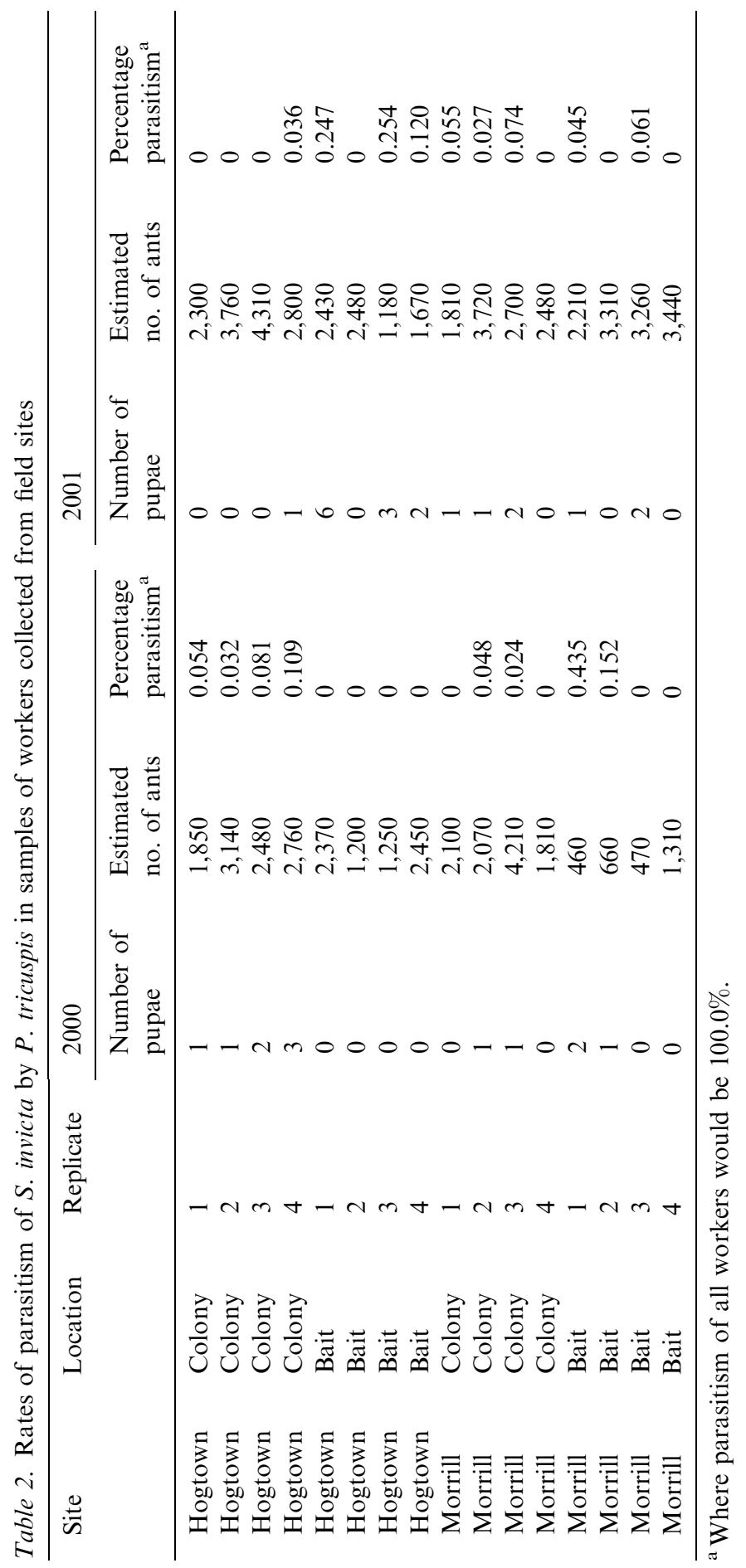




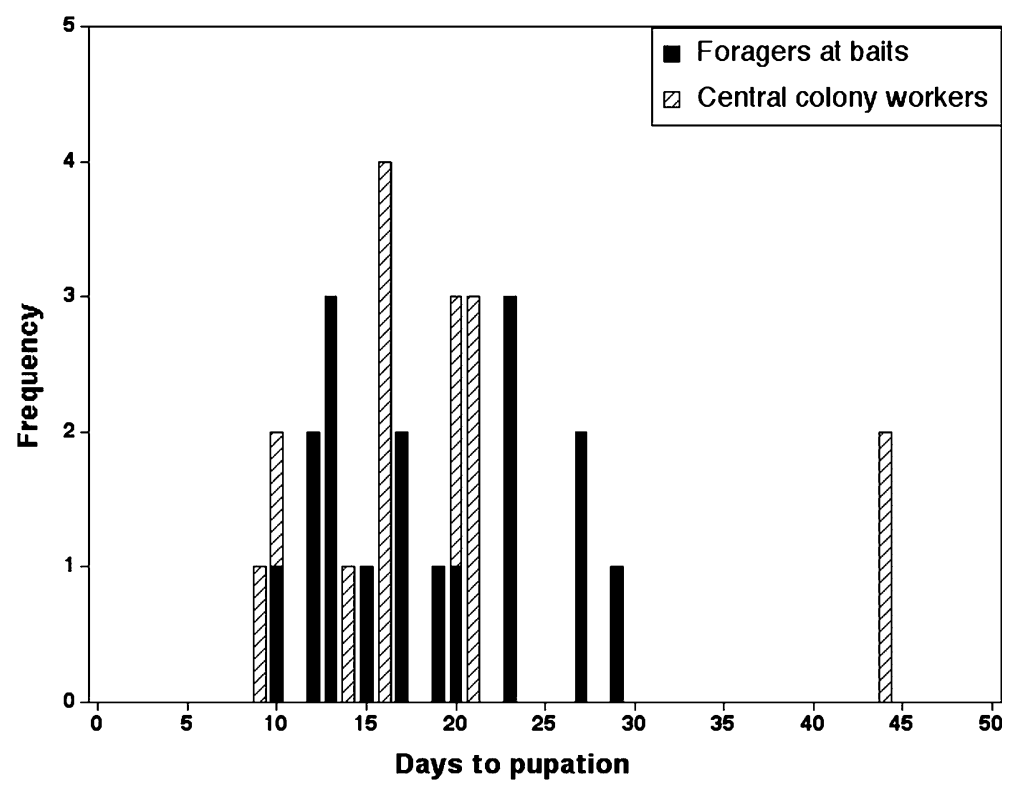

Figure 3. Histogram of the number of pupae found as a function of approximate days after collection of workers from field colonies. Solid bars represent workers collected at baits; striped bars represent workers collected from the central colony.

off by 2 days (see Methods), there would still be a 6-day period of no pupariation. Parasitized workers within 6-10 days of pupariation (or longer, see Discussion) apparently escaped our collection methods, and thus our figures underestimate the actual rate of parasitism.

\section{Fire ant densities}

Estimated densities of $S$. invicta workers in the sample areas where P. tricuspis was collected ranged from $>14$ million/ha at Hogtown Creek to $>29$ million/ha at Sanders Ranch (Table 1). Both host ant density and adult phorid abundance were higher at Sanders Ranch compared to either of the other two sites.

\section{Discussion}

Phenology and abundance

Introduced populations of $P$. tricuspis were active throughout the year, with highest densities observed in November. In Sao Paulo State, 
Brazil, from which this population was imported, P. tricuspis is also active year-round (Fowler et al., 1995). Although winters in Florida are relatively mild, temperatures drop below those in Sao Paulo. Air temperatures below $\sim 20{ }^{\circ} \mathrm{C}$ appear to represent a physiological barrier to flight activity in P. tricuspis (S.D. Porter et al., in preparation), as well as some other Pseudacteon species (Morrison et al., 1999a). In a study conducted in central Texas, Pseudacteon phorids that parasitized $S$. geminata were not active from January through March, even on days when air temperatures rose above $20^{\circ} \mathrm{C}$ (Morrison et al., 1999a).

Pseudacteon tricuspis was active on warm days $\left(>20^{\circ} \mathrm{C}\right)$ during the winter months in north central Florida, but it was not active on days when temperatures did not reach $20{ }^{\circ} \mathrm{C}$ (LWM unpublished data). In regions that are more temperate, $P$. tricuspis may not be active on warm days in the winter months. The aboveground foraging activity of S. invicta, however, decreases as soil temperatures fall below $22^{\circ} \mathrm{C}$ and ceases at $15^{\circ} \mathrm{C}$ (Porter and Tschinkel, 1987), so relatively few hosts would be available in the winter months in cooler regions.

The wide range of spatial and temporal variability in abundance documented for P. tricuspis appears to be characteristic of Pseudacteon ant parasitoids in general; similar patterns have been reported from Pseudacteon species native to Texas (Morrison et al., 1999a, 2000). Such variability is likely the result of the short lifespan of the adult in conjunction with spatio-temporal variation in the availability of hosts, which may be greatly influenced by climatic conditions (Morrison et al., 1999a, 2000).

Sex determination in P. tricuspis is dependent upon the size of the worker host, with females typically emerging from larger workers (Morrison et al., 1999b). Thus secondary sex ratios observed in the field may be indicative of the size range of worker ants available for parasitism. Male-biased sex ratios have been reported for other species of Pseudacteon phorids attacking Solenopsis ants (Pesquero et al., 1993; Fowler et al., 1995; Morrison et al., 1999a, 2000), and a discussion of the potential mechanisms underlying this phenomenon is presented in Morrison and Gilbert (1998).

\section{Parasitism rates}

Assuming parasitism of workers in the field occurred continuously at a similar rate before our collections, we would expect to find pupae from day 1. Similarly, because the median time to pupation at $27^{\circ} \mathrm{C}$ is 21 days (SDP, unpublished data), we would expect similar numbers of pupae for the first 3 weeks after collection. The absence of pupariation 
within the first 6-10 days after collection of workers indicates that parasitism by P. tricuspis induces behavioral changes in the host worker. Such parasitized workers appear not to be present in the central portion of the colony and not to recruit to rich food resources. These workers may have been located deeper underground or in side tunnels. Although it is unknown where these parasitized workers are during this period, they must remain alive for the larvae to pupariate. Field collections of Solenopsis fire ants (from shallow excavations of the central colony) parasitized by other species of Pseudacteon in South America revealed a similar pattern, with no pupations occurring within the first 3 days of collection, followed by a peak 9 days after collection (SDP, unpublished data).

In a separate laboratory study in which S. invicta workers were exposed to $P$. tricuspis attack in laboratory arenas, pupariation in $P$. tricuspis began at 11 days after oviposition, peaked at 18 days, and declined to near zero at 42 days (at a constant $27^{\circ} \mathrm{C}$ ), although rare pupariations occurred until day 64 (Figure 4). Thus the observed distribution from our field collections (Figure 3 ) could potentially be obtained from ovipositions spanning only a few days. The mechanism underlying a shift in behavior of the parasitized worker could be the

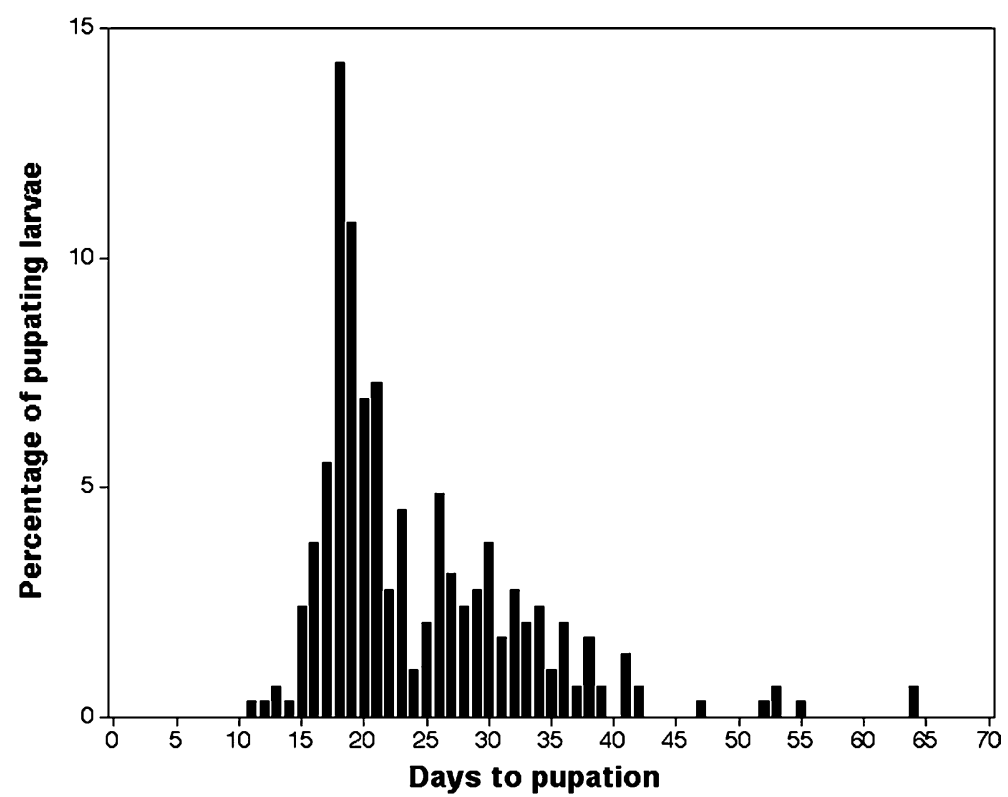

Figure 4. Frequency distribution of time to pupation by $(n=288)$ Pseudacteon tricuspis larvae infecting Solenopsis invicta workers maintained at a constant $27{ }^{\circ} \mathrm{C}$ in the laboratory. All workers were parasitized within an 8-h period at the beginning of the trials. 
migration of the larva to the head capsule, which occurs 3-4 days following oviposition (Porter et al., 1995a).

Thus, actual parasitism rates may be several times higher than reported here. Even if our estimates underestimate true rates by as much as an order of magnitude, however, parasitism rates are still low in an absolute sense, and the biological relevance of our findings is not changed. It should be noted that parasitism rates were determined from collections of workers made in November, which is the month with the highest abundance of flies at two of the three sites. Thus parasitism rates may be lower at other times of the year.

The low parasitism rates reported here are consistent with those of other phorid parasitoid/ant host associations documented in the literature. A similar study of native Pseudacteon species attacking S. geminata in Texas reported parasitism rates of $<3 \%$ (Morrison et al., 1997). Feener (1988) found that parasitism rates for Apocephalus phorids attacking Pheidole workers were $<5 \%$ for $P$. dentata in Texas and $<2 \%$ for P. titanis in Mexico. Early investigations of Pseudacteon phorids attacking Solenopsis fire ants in their native South American homeland reported that "relatively small numbers" of workers were attacked (Jouvenaz et al., 1981).

\section{Reconciliation of parasitism rates and adult fly densities}

Although field parasitism rates were found to be quite small, observed rates can be reconciled with the relatively high observed adult fly abundances, due to the great density of $S$. invicta workers present at the sites. Unfortunately, it is not possible to make accurate predictions of expected fly numbers, due to our lack of knowledge of the number of workers in a colony that would be available for attack (i.e., some workers are not of the right size or do not engage in behaviors that attract flies [see below]), the degree to which our observed parasitism rates underestimate true parasitism rates, the longevity of adult phorids, and the distance over which adult phorids may locate and parasitize hosts. It seems reasonable, however, that very low parasitism rates may support relatively abundant populations of Pseudacteon adults, at least in areas with high densities of host ants.

\section{Implications}

The direct effect of mortality due to parasitism of $S$. invicta by $P$. tricuspis at our sites was very small. Solenopsis workers have numerous adaptations and behaviors that allow them to avoid parasitism by 
Pseudacteon phorids (Morrison, 1999). Some of these responses, however, may be so dramatic that the Solenopsis colony is put at a competitive disadvantage relative to other ant species (i.e., an indirect effect; Morrison, 1999). For example, Solenopsis workers have been documented to obtain less food and even lose food resources to competing ants when Pseudacteon phorids are present (Feener and Brown, 1992; Orr et al., 1995; Porter et al., 1995b; Morrison, 1999).

The population of P. tricuspis released into north central Florida is not attracted to forging $S$. invicta workers per se, although it is strongly attracted to aggressive interactions with non-nestmate workers, mound disturbances, mating flights, and other activities where alarm pheromones are released (Morrison and King, 2004). Thus, to substantially impact $S$. invicta populations, this parasitoid would have to have relatively large indirect effects on aggressive interactions with non-nestmate workers, mound disturbances, mating flights, and other activities where alarm pheromones are released.

A multi-year, large-scale field experiment conducted in north central Florida found no measurable effect of introduced $P$. tricuspis phorids on host S. invicta populations (L.W. Morrison and S.D. Porter, in review). Introduced phorid populations may require many years, or multiple phorid species may need to be introduced, before a measurable impact is apparent. Alternatively, phorid fly parasitoids may not be a major factor regulating fire ant populations.

\section{Acknowledgments}

L.R. Davis, Jr., assisted with field sampling. S. Jester, D. Kelly, and M. Romero assisted with laboratory work. J. A. Briano and J. T. Vogt made helpful comments on the manuscript. The USDA's National Research Initiative Competitive Grants Program, award \#99-35316-7849, supported this work. The use of trade, firm, or corporation names in this publication is for the information and convenience of the reader. Such use does not constitute an official endorsement or approval by the United States Department of Agriculture or the Agricultural Research Service of any product or service to the exclusion of others that may be suitable.

\section{References}

Anon., 1999. Fire ant invades southern California. California Agric. 53: 5.

Banks, W.A., C.S. Lofgren, D.P. Jouvenaz, C.E. Stringer, P.M. Bishop, D.F. Williams, D.P. Wojcik and B.M. Glancey, 1981. Techniques for collecting, rearing, and handling imported fire ants, USDA, SEA, AATS-S-21, p. 9 
Briano, J., D. Jouvenaz, D. Wojcik, R. Patterson and H. Cordo, 1995. Protozoan and fungal diseases in Solenopsis richteri and S. quinquecuspis (Hymenoptera: Formicidae) in Buenos Aires Province, Argentina. Florida Entomol. 78: 531-537.

Callcott, A.-M.A. and H.L. Collins, 1996. Invasion and range expansion of red imported fire ant (Hymenoptera: Formicidae) in North America from 1918-1995. Florida Entomol. 79: 240-251.

Davidson, N.A. and N.D. Stone, 1989. Imported fire ants. In: D.L. Dahlsten, R. Garcia and H. Lorraine (eds), Eradication of Exotic Pests. Yale University Press, New Haven, CT. pp. 196-217.

Davis, L.R., Jr., R.K. Vander Meer and S.D. Porter, 2001. Red imported fire ants expand their range across the West Indies. Florida Entomol. 84: 735-736.

Feener, D.H., Jr., 1988. Effects of parasites on foraging and defense behavior of a termitophagous ant, Pheidole titanis Wheeler (Hymenoptera: Formicidae). Behav. Ecol. Sociobiol. 22: 421-427.

Feener, D.H., Jr. and B.V. Brown, 1992. Reduced foraging of Solenopsis geminata (Hymenoptera: Formicidae) in the presence of parasitic Pseudacteon spp. (Diptera: Phoridae). Ann. Entomol. Soc. Am. 85: 80-84.

Fowler, H.G., M.A. Pesquero, S. Campiolo and S.D. Porter, 1995. Seasonal activity of species of Pseudacteon (Diptera: Phoridae) parasitoids of fire ants (Solenopsis saevissima) (Hymenoptera: Formicidae) in Brazil. Cientifica 23: 367-371.

Harris, R., 2001. Blantant Breaches of the Border. Stowaways 1: 11.

Jouvenaz, D.P., C.S. Lofgren and W.A. Banks, 1981. Biological control of imported fire ants: A review of current knowledge. Bull. Entomol. Soc. Am. 27: 203-208.

Lockley, T.C. and H.L. Collins, 1990. Imported fire ant quarantine in the United States of America: past, present, and future. J. Mississippi Acad. Sci. 35: 23-26.

Macom, T.E. and S.D. Porter, 1996. Comparison of polygyne and monogyne red imported fire ants (Hymenoptera: Formicidae) population densities. Ann. Entomol. Soc. Am. 89: 535-543.

Morrison, L.W., 1999. Indirect effects of phorid fly parasitoids on the mechanisms of interspecific competition among ants. Oecologia 121: 113-122.

Morrison, L.W., 2000. Biology of Pseudacteon (Diptera: Phoridae) ant parasitoids and their potential to control imported Solenopsis fire ants (Hymenoptera: Formicidae). Recent Research Developments in Entomology. Trivandrum, India, Research Signpost. 3: 1-13.

Morrison, L.W. and L.E. Gilbert, 1998. Parasitoid-host relationships when host size varies: the case of Pseudacteon flies and Solenopsis fire ants. Ecol. Entomol. 23: 409416.

Morrison, L.W. and J.R. King, 2004. Host location behavior in a parasitoid of imported fire ants. J. Insect Behav. 17: 367-383.

Morrison, L.W., C.G. Dall'Agilo-Holvorcem and L.E. Gilbert, 1997. Oviposition behavior and development of Pseudacteon flies (Diptera: Phoridae), parasitoids of Solenopsis fire ants (Hymenoptera: Formicidae). Environ. Entomol. 26: 716-724.

Morrison, L.W., E.A. Kawazoe, R. Guerra and L.E. Gilbert, 2000. Ecological Interactions of Pseudacteon parasitoids and Solenopsis ant hosts: environmental correlates of activity and effects on competitive hierarchies. Ecol. Entomol. 25: 433-444.

Morrison, L.W., E.A. Kawazoe, R. Guerra and L.E. Gilbert, 1999a. Phenology and dispersal in Pseudacteon flies (Diptera: Phoridae), parasitoids of Solenopsis fire ants (Hymenoptera: Formicidae). Ann. Entomol. Soc. Am. 92: 198-207. 
Morrison, L.W., S.D. Porter and L.E. Gilbert, 1999b. Sex ratio variation as a function of host size in Pseudacteon flies (Diptera: Phoridae), parasitoids of Solenopsis fire ants (Hymenoptera: Formicidae). Biol. J. Linn. Soc. 66: 257-267.

Morrison, L.W., S.D. Porter, E. Daniels and M.D. Korzukhin, 2004. Potential global range expansion of the invasive fire ant, Solenopsis invicta. Biol. Invasions 6: 183-191.

Nattrass, R. and C. Vanderwoude, 2001. A preliminary investigation of the ecological effects of Red Imported Fire Ants (Solenopsis invicta) in Brisbane. Ecological Management and Restoration 2: 220-223.

Orr, M.R., S.H. Seike, W.W. Benson and L.E. Gilbert, 1995. Flies suppress fire ants. Nature 373: 292-293.

Pesquero, M.A., S. Campiolo and H.G. Fowler, 1993. Phorids (Diptera: Phoridae) associated with mating swarms of Solenopsis saevissima (Hymenoptera: Formicidae). Florida Entomol. 76: 179-181.

Porter, S.D., 1998. Biology and behavior of Pseudacteon decapitating flies (Diptera: Phoridae) that parasitize Solenopsis fire ants (Hymenoptera: Formicidae). Florida Entomol. 81: 292-309.

Porter, S.D. and W.R. Tschinkel, 1987. Foraging in Solenopsis invicta (Hymenoptera: Formicidae): effects of weather and season. Environ. Entomol. 16: 802-808.

Porter, S.D., M.A. Pesquero, S. Campiolo and H.G. Fowler, 1995a. Growth and development of Pseudacteon phorid fly maggots (Diptera: Phoridae) in the heads of Solenopsis fire ant workers (Hymenoptera: Formicidae). Environ. Entomol. 24: 475479.

Porter, S.D., R.K. Vander Meer, M.A. Pesquero, S. Campiolo and H.G. Fowler, 1995b. Solenopsis (Hymenoptera: Formicidae) fire ant reactions to attacks of Pseudacteon flies (Diptera: Phoridae) in Southeastern Brazil. Ann. Entomol. Soc. Am. 88: 570575 .

Porter, S.D., L.A. Nogueira de Sá and L.W. Morrison, 2004. Establishment and dispersal of the fire ant decapitating fly Pseudacteon tricuspis in North Florida. Biol. Control 29: 179-188.

Stimac, J.L., R.M. Pereira, S.B. Alves and L.A. Wood, 1993. Beauveria bassiana (Balsamo) Vuillemin (Deuteromycetes) applied to laboratory colonies of Solenopsis invicta Buren (Hymenoptera: Formicidae) in soil. J. Econ. Entomol. 86: 348-352.

Williams, D.F., D.H. Oi and G.J. Knue, 1999. Infection of red imported fire ant (Hymenoptera: Formicidae) colonies with the entomopathogen Thelohania solenopsae (Microsporidia: Thelohaniidae). J Econ. Entomol. 92: 830-836.

Williams, D.F., H.L. Collins and D.H. Oi, 2001. The Red Imported Fire Ant (Hymenoptera: Formicidae): An Historical Perspective of Treatment Programs and the Development of Chemical Baits for Control. American Entomologist 47: 146-159. 